\title{
Trends and risk factors for hepatitis A in NSW, 2000-2009: the trouble with travel
}

\author{
Evan Freeman $^{\mathrm{A}, \mathrm{B}, \mathrm{D}}$, Siranda Torvaldsen ${ }^{\mathrm{B}}$, \\ Sean Tobin ${ }^{\mathrm{C}}$, Glenda Lawrence ${ }^{\mathrm{B}}$ \\ and C. Raina MacIntyre ${ }^{\mathrm{B}}$ \\ ${ }^{\mathrm{A}}$ NSW Public Health Officer Training Program, \\ NSW Ministry of Health \\ ${ }^{\mathrm{B}}$ School of Public Health and Community Medicine, \\ The University of New South Wales \\ ${ }^{\mathrm{C}}$ Communicable Diseases Branch, NSW Ministry of Health \\ ${ }^{\mathrm{D}}$ Corresponding author.Email: efree@doh.health.nsw.gov.au
}

\begin{abstract}
Aim: To analyse trends in hepatitis A notifications and information on exposure to risk factors, in particular international travel, collected through routine surveillance in NSW. Methods: Hepatitis A notification data for the period 2000-2009 were extracted from the Notifiable Diseases Database and analysed by age group, gender, area of residence and exposure risk factors, including travel, food eaten and contact with other possible infectious cases. Results: The notification rate for hepatitis A in NSW fell from 3.0 cases per 100000 population in 2000 to 1.4 cases per 100000 population in 2009. Notification rates were highest among people aged 20-24 years and residents of metropolitan Sydney. Travel to a country where hepatitis A is endemic was a risk exposure identified in $43 \%$ of cases. Conclusion: International travel to highly endemic countries continues to be the most common risk factor for hepatitis A infection notified in NSW despite recommendations that travellers be vaccinated prior to travel to these areas.
\end{abstract}

faecal-oral route, most frequently from close contacts such as household members. Less common routes of exposure include ingestion of contaminated water and food sources. ${ }^{3}$ Other risk groups in which there were large outbreaks of hepatitis A in the 1990s include men who have sex with men and intravenous drug users. ${ }^{4,5}$

The onset of signs and symptoms of acute hepatitis A infection are usually abrupt and include fever, malaise, anorexia, nausea, abdominal discomfort, dark urine and jaundice. ${ }^{6}$ In infants and children aged less than 5 years, symptoms are mild or absent in more than $80 \%$ of cases. ${ }^{2}$ In adults, symptoms are more pronounced and potentially life-threatening if underlying liver disease is present. ${ }^{6}$ The incubation period of hepatitis A ranges from 15 to 50 days with an average of 20-30 days, whilst the duration of signs and symptoms of infection vary between individuals but normally resolve within 2 months of onset. ${ }^{3}$ The communicability of hepatitis A virus infection starts at up to 2 weeks before the onset of prodromal symptoms and ceases 1 week after onset of jaundice. Following infection with hepatitis A virus, lifetime immunity is usually conferred. ${ }^{2,3}$

Travel by individuals from low hepatitis A incidence countries, such as Australia, to countries with higher endemicity has emerged as a preventable risk factor. ${ }^{7,8} \mathrm{~A}$ review of New South Wales (NSW) hepatitis A notification data conducted in $2006^{9}$ found that travel to countries with moderate to high hepatitis A endemicity was a risk factor for more than $50 \%$ of notified cases. A highly effective vaccine has been available in Australia since 1994, ${ }^{6}$ and is recommended prior to travel to endemic areas. ${ }^{10}$

The aim of this study was to examine trends in hepatitis A notifications in NSW for the period 2000-2009 and review data on exposure to hepatitis A risk factors identified through routine surveillance. A focus was whether international travel continued to be the most important risk factor.

\section{Methods}

Doctors, hospitals and laboratories in NSW are required to notify the local public health unit of cases of hepatitis A under the direction of the NSW Public Health Act 1991.* A confirmed diagnosis requires serological detection of 


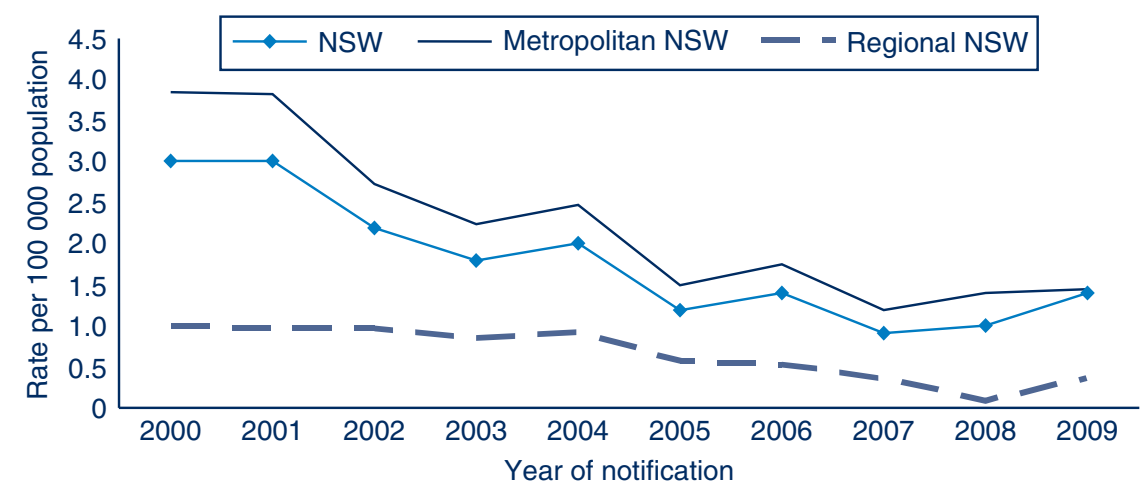

Figure 1. Comparison of annual hepatitis A notification rate per 100000 population for regional and metropolitan residents of NSW, 2000-2009.

Source: NSW Health Notifiable Diseases Database (now known as the Notifiable

Conditions Information Management System).

anti-hepatitis A IgM, in the absence of recent vaccination, or detection by nucleic acid testing. ${ }^{11}$ Public health unit staff are required to collect demographic and risk factor information for incident cases and enter this data into the Notifiable Diseases Database (NDD) (known since 2010 as the Notifiable Conditions Information Management System). This information includes age, gender, Aboriginality, area health service of residence and self-reported hospitalisation. Hepatitis A notifications were extracted from the NDD for the period 2000-2009 using the NSW Health data warehouse, HOIST (Health Outcomes Information Statistical Toolkit). Australian Bureau of Statistics mid-year population estimates were used to calculate crude annual notification rates.

The exposure information recorded in the NDD was travel history and country of travel, household contact of a hepatitis A case, eating raw shellfish, male-to-male sexual contact, exposure to raw sewage, drug use and attendance at child-care centres. We also performed subanalyses of exposure and hospitalisation information by age group.

\section{Results}

There were 1203 notifications of hepatitis A in NSW between 2000 and 2009. The highest number of notifications was reported in $2001(n=200)$ and the lowest in 2007 $(n=65)$. Since 2005, there have been fewer than 100 notifications each year. Annual notification rates of hepatitis A in NSW have remained stable at less than 3.0 per 100000 population since 2001 (Figure 1). After falling to a low of 0.9 per 100000 population in 2007, the rate increased to 1.4 per 100000 population by 2009 (rates per 100000 are yearly rates unless otherwise specified). Hepatitis A notifications rates were two- to three-fold higher in metropolitan populations compared with regional populations (Figure 1). Only 19 people were identified as Aboriginal from all notifications: a 10 -year notification rate of 1.2 case-patients per 100000 population.

\section{Age and gender}

The age range of individuals notified with hepatitis $\mathrm{A}$ in NSW was 11 months to 97 years with $50 \%$ of cases between the ages of 20 and 44 years. The 20-24-year age group had the highest notification rate for hepatitis A of 3.2 per 100000 population (Figure 2), while the notification rate was below 1.0 per 100000 population in the age groups over 54 years.

Overall, $62 \%$ of notifications were in males, however the gender imbalance decreased over the review period. During the first 5 years (2000-2004), 66\% of notifications were in males, while $53 \%$ of notifications during the last 5 years (2005-2009) were in males.

\section{Hospitalisation}

Twenty-one percent $(n=252)$ of all notified cases between 2000 and 2009 for whom data were collected reported a period of hospitalisation during their infection. Of these, $57 \%(n=143)$ were male. The highest hospitalisation rate was 0.6 per 100000 population in the 20-24-year and $25-29$-year age groups. All other age groups had hospitalisation rates of 0.5 per 100000 population or lower.

\section{Risk factors}

Of the 1203 hepatitis A notifications, risk factor information was identified and recorded for 886 (74\%). Travel to an endemic area or being a household contact of someone who had recently travelled to an endemic area were the most frequently identified risk factors. Together, these accounted for $69 \%$ of cases with documented risk factor information (Table 1). Where contact with a recently notified case of hepatitis A was reported, most cases identified a household member as the source case.

Identification of male-to-male sexual contact has declined as an exposure risk to hepatitis $\mathrm{A}$, recorded in $53(6 \%)$ 


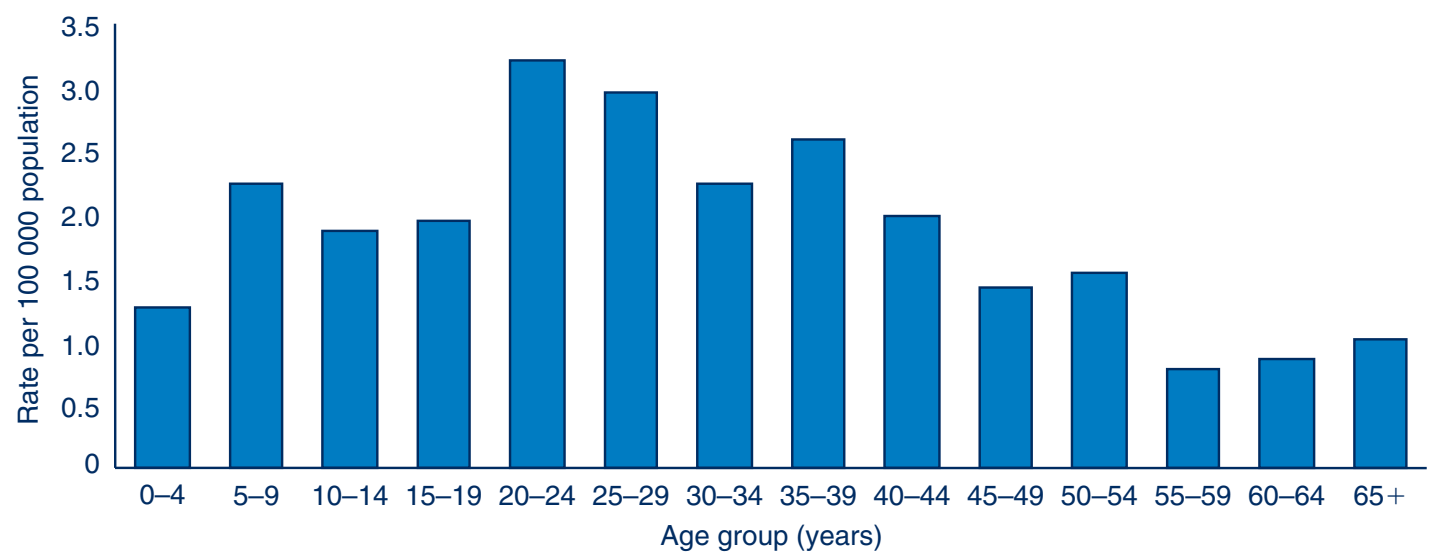

Figure 2. Hepatitis A notification rate per 100000 population, NSW, 2000-2009, by age group. Source: NSW Health Notifiable Diseases Database (now known as the Notifiable Conditions Information Management System).

Table 1. Risk factors reported by notified hepatitis A cases, NSW, 2000-2009

\begin{tabular}{lrr}
\hline Risk factor $^{\text {a }}$ & $n$ & $\%$ \\
\hline & & 411 \\
Travel to endemic areas & 205 & 46 \\
Household contact of a case that travelled to an endemic area & 74 & 23 \\
Ate raw shellfish & 69 & 80 \\
Contact with another possible case & 29 & 8 \\
Male-to-male sexual contact & 25 & 7 \\
Recreational drug use & 13 & 3 \\
Contact with raw sewage & 886 & 3 \\
Attends child-care centre & & 1 \\
Total & & - \\
\hline${ }^{a}$ Categories are not mutually exclusive. & & \\
Source: NSW Health Notifiable Diseases Database (now known as the Notifiable Conditions Information Management System).
\end{tabular}

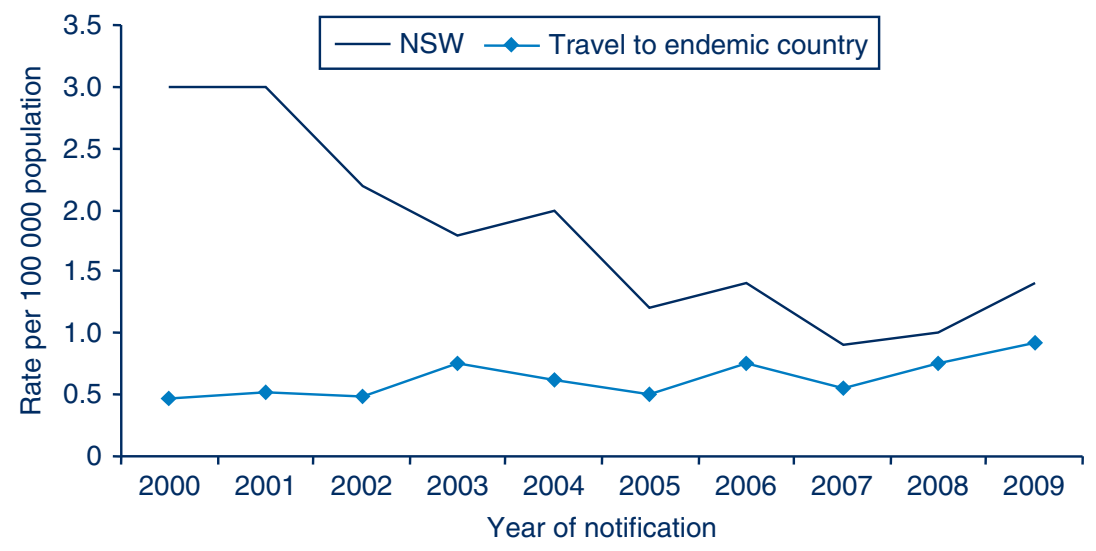

Figure 3. Annual hepatitis A notification rate per 100000 population, NSW, 2000-2009, and the rate for cases with travel as an identified risk factor. Source: NSW Health Notifiable Diseases Database (now known as the Notifiable Conditions Information Management System).

notified cases during 2000-2004 and only in seven (1\%) for 2005-2009.

Notification rates of cases with any travel history as a risk factor increased from 0.76 per 100000 population in 2008 to 0.92 per 100000 population in 2009 (Figure 3). The highest proportion of notified cases with travel recorded as a risk factor was $77 \%$ in 2008 . This decreased to $65 \%$ in 2009 , however, the overall notification rate increased from 1.0 per 100000 to 1.5 per 100000 in the same period. 


\section{Region of travel}

International travel was identified as a primary risk factor for exposure to hepatitis A in $49 \%(n=431)$ of all notifications; 411 (95\%) of these had a history of recent travel to countries with moderate-to-high hepatitis A endemicity. This group had a median age at onset of infection of 22 years compared to a median of 32 years in cases where travel was not implicated. The regions of travel identified included South and South East Asia (44\%), West and Central Asia (16\%), Oceania (19\%) and East Asia (6\%). Travellers acquiring hepatitis A in West and Central Asian countries had the youngest median age at onset of 14 years, whereas the median age was 28 years among those travelling to other regions. The destinations most frequently recorded by cases included India, Lebanon, Pakistan, Indonesia, Fiji and Vanuatu.

\section{Discussion}

The notification rate of hepatitis A in NSW has remained stable at less than three cases per 100000 population since 2001, with metropolitan populations experiencing much higher notification rates than regional areas of NSW. The notification rate was highest in the 20-29-year age group, and lowest in adults aged 55 years and older. Risk factors for exposure to hepatitis A such as male-to-male sexual contact and recreational drug use consistently declined in frequency over the period analysed, while travel to countries with moderate-to-high levels of endemicity has increased. Being a household contact and eating raw shellfish continued to be reported as risk factors. During the period of analysis there were no large scale foodborne outbreaks of hepatitis in NSW, although an increase in hepatitis A notifications in 2009 has been linked to semidried tomatoes in Victoria. ${ }^{12}$

This study used passive surveillance data which were limited by case reports with incomplete information on hepatitis A risk factors. Missing information may reduce the accuracy of the true prevalence of risk behaviours, as self-reporting can increase or decrease the incidence of behaviours such as male-to-male sexual contact and recreational drug use. Having experienced public health practitioners investigate case-patients improves the collection of accurate information while more complete case reports, including risk factor information, would enhance the usefulness of hepatitis A surveillance data.

The lowest hepatitis notification rate was in people aged 55 years and over. This age group has similar travel risks to younger people, with an Australian study from 2003 finding that travel to endemic countries was not more common in younger people than among older age groups. ${ }^{13}$ Lower hepatitis A notification rates in people older than 55 years may be due to exposure to hepatitis A earlier in life, before improvements to sanitation infrastructure, and to the availability of hepatitis A vaccination. ${ }^{2}$ Nationally, the annual hepatitis A notification rate has declined substantially from more than 50 cases per 100000 population in 1970 , to two per 100000 population between 2003 and 2005 . $^{1}$

The low notification rates in young children may not reflect a low incidence of hepatitis $\mathrm{A}$, as young children are more likely to have unrecognised or asymptomatic disease, which has been linked to sustained hepatitis A virus transmission in the community. ${ }^{14}$ The hospitalisation rate was highest in young adults aged 20-29 years at 0.6 per 100000 population, which reflects the increase of recognisable symptoms in adults with hepatitis A. ${ }^{6}$ National notification data show higher hospitalisation rates in this age group, with the highest among males aged 34-59 years and females aged 60 years and over. ${ }^{1}$ Aboriginal populations have high rates of hepatitis A immunity; this group have been notified and hospitalised with hepatitis A more often than non-Indigenous populations of Australia. ${ }^{15}$ The targeted Indigenous hepatitis A vaccination program for the Top End of Australia excludes Indigenous children in NSW so we would not expect to see any impact of vaccination in NSW Aboriginal populations, in whom rates of hepatitis $\mathrm{A}$ in the absence of vaccination programs are high. ${ }^{16}$

Travel to countries of higher endemicity was the most important risk factor for acquiring hepatitis A among NSW cases, which confirms the results of a 2006 study that found that travel to these areas is a risk exposure for hepatitis A in NSW. ${ }^{9}$ In 2002, travel was added as an exposure risk to be reported for each notified case of hepatitis A in NSW, which has resulted in improved recording of risk factor information over the period of analysis. By 2003, the average number of Australians travelling overseas on short holidays (less than 3 months) was 300000 per month. ${ }^{17}$ There has been a $72 \%$ increase to 517000 travellers per month in 2009. ${ }^{17}$ Studies in the United States of America and Canada have also identified that travel to countries with high endemicity is a common risk factor for acquisition of hepatitis A. ${ }^{14,18}$

Consultation for pre-travel health advice is an important opportunity for travellers to receive hepatitis A vaccination. A survey of pre-travel advice-seeking behaviour among Australian travellers identified low levels of advice seeking with only $33 \%$ of 503 surveyed travellers visiting a doctor or travel health clinic prior to their last international trip. For travellers to areas of high endemicity for hepatitis A or B, 41\% had sought pre-travel advice with almost half of those obtaining pre-travel vaccination. ${ }^{13}$ In comparison, a recent survey of Canadians found that only $24 \%$ of travellers to endemic countries had been vaccinated against hepatitis A. ${ }^{19}$ Measures that increase the awareness and uptake of pre-travel vaccination of hepatitis A are likely to reduce the incidence of hepatitis A and its local transmission in the community. Any reduction in the 
incidence of hepatitis A will have benefits for individuals as well as reduce the need for treatment and public health response.

\section{Conclusion}

The hepatitis A notification rate has remained stable in NSW and the most common risk factor for hepatitis A in NSW continued to be travel to countries of moderate-tohigh endemicity or being a household contact of a person with hepatitis A infection who has travelled to one of these countries. Strategies that effectively inform the travelling public about the risks posed by hepatitis A and increase the uptake of pre-travel vaccination are likely to reduce the burden of hepatitis A in NSW.

\section{Acknowledgment}

This work was completed while EF was an employee of the NSW Public Health Officer Training Program, funded by the NSW Ministry of Health. The Program is offered in partnership with the University of New South Wales. He undertook this work while based at the Communicable Diseases Branch, NSW Ministry of Health.

\section{References}

1. Brotherton J, Wang H, Schafer A, Quinn H, Menzies R, Lawrence $\mathrm{G}$ et al. Vaccine preventable diseases and vaccination coverage in Australia, 2003 to 2005. Commun Dis Intell 2007; 31: S1-152.

2. World Health Organization. Hepatitis A. WHO/CDS/CSR/ EDC/2000.7 Available at: http://www.who.int/csr/disease/ hepatitis/HepatitisA_whocdscsredc2000_7.pdf (Cited 12 December 2011).

3. American Public Health Association. Heyman DL, editor. Control of communicable diseases manual (19th Edition). Washington DC: American Public Health Association; 2008.

4. Stokes ML, Ferson MJ, Young LC. Outbreak of hepatitis among homosexual men in Sydney. Am J Public Health 1997; 87: 2039-41. doi:10.2105/AJPH.87.12.2039

5. Delpech VC, Thackway SV, Young L, Pontivivo G, Smedley E, Morgan K et al. Hepatitis A in south-eastern Sydney 1997-1999: continuing concerns for gay men and an outbreak among illicit drug users. Commun Dis Intell 2000; 24: 203-6.

6. Amin J, Gilbert G, Escott R, Heath T, Burgess M. Hepatitis A epidemiology in Australia: national seroprevalence and notifications. Med J Aust 2001; 174: 338-41.

7. Health Canada. A review of provincial/territorial strategies for hepatitis A pre- and post-exposure prophylaxis. Can Commun Dis Rep 2005; 31: 197-205. Available at: www.phac-aspc.gc.ca/ publicat/ccdr-rmtc/05vol31/dr3124e-eng.php (Cited 12 December 2011).
8. Advisory Committee on Immunization Practices (ACIP) Centers for Disease Control and Prevention. (CDC). Update: Prevention of hepatitis A after exposure to hepatitis A virus and in international travelers. Updated recommendations of the Advisory Committee on Immunization Practices (ACIP). MMWR Morb Mortal Wkly Rep 2007; 56: 1080-4.

9. Ward K, McAnulty J. Hepatitis A: who in NSW is most at risk of infection? NSW Public Health Bull 2008; 19: 32-5. doi:10.1071/ NB07100

10. National Health and Medical Research Council. Australian Immunisation Handbook. 9th Ed. Canberra: Commonwealth of Australia; 2008.

11. NSW Health. Control guidelines. Hepatitis A. National Guidelines for Public Health Units. Last updated: 1 October 2009. Available at: www.health.nsw.gov.au/factsheets/guideline/ hepa.html (Cited 12 December 2011).

12. OzFoodNet Working Group. OzFoodNet quarterly report. 1 October to 31 December 2009. Commun Dis Intell 2010; 34 : 59-67.

13. Zwar N, Streeton CL. Travel Health Advisory Group. Pretravel advice and hepatitis A immunization among Australian travelers. J Travel Med 2007; 14: 31-6. doi:10.1111/j.17088305.2006.00088.x

14. Advisory Committee on Immunization Practices (ACIP). Fiore AE, Wasley A, Bell BP. Prevention of hepatitis A through active or passive immunization: recommendations of the Advisory Committee on Immunization Practices (ACIP). MMWR Recomm Rep. 2006; 55(RR-7): 1-23. Available at: http://www. cdc.gov/mmwr/PDF/rr/rr5507.pdf (Cited 12 December 2011).

15. Menzies R, Turnor C, MacIntyre PB. Vaccine preventable diseases and vaccination coverage in Aboriginal and Torres Strait Islander people, Australia, 2003 to 2006. Commun Dis Intell 2008; 32(Suppl): S2-67.

16. MacIntyre CR, Burgess M, Isaacs D, McIntyre PB, Menzies R, Hull B. Epidemiology of severe hepatitis A in Indigenous Australian children. J Paediatr Child Health 2007; 43: 383-7. doi:10.1111/j.1440-1754.2007.01084.x

17. Australian Bureau of Statistics. 3401.0 - Overseas Arrivals and Departures, Australia, Jun 2010. Table 7. Short-term movement, resident departures - selected destinations: trend. Available at: http://www.abs.gov.au/AUSSTATS/abs@.nsf/ DetailsPage/3401.0Jun\%202010?OpenDocument (Cited 12 December 2011).

18. Scheifele DW, Serres G, Gilca V, Duval B, Milner R, Ho M et al. A nationwide survey of past hepatitis A infections among Canadian adults. Vaccine 2010; 28: 5174-8. doi:10.1016/ j.vaccine.2010.05.076

19. Duval B, De Serre G, Shadmani R, Boulianne N, Pohani G, Naus M. et al. A population-based comparison between travelers who consulted travel clinics and those who did not. J Travel Med 2003; 10: 4-10. doi:10.2310/7060.2003.30659 